\title{
Electronic prescriptions: opportunities and challenges for the patient and pharmacist
}

This article was published in the following Dove Press journal:

Advanced Health Care Technologies

3 February 2016

Number of times this article has been viewed

\author{
Ashley E Lanham' \\ Gary L Cochran² \\ Donald G Klepser ${ }^{2}$ \\ 'National Association of Chain \\ Drug Stores (NACDS) Foundation, \\ Arlington, VA, USA; ${ }^{2}$ Department \\ of Pharmacy Practice, College of \\ Pharmacy, University of Nebraska \\ Medical Center, Omaha, NE, USA
}

\begin{abstract}
Electronic-prescribing (e-prescribing) is one part of the larger move to increased utilization of health information technologies (HITs). Along with other HITs such as electronic health records and health information exchanges, e-prescribing is seen as a tool for improving patient-centered care. The potential benefits of e-prescribing are meant to extend to prescribers, payers, pharmacies, and patients. In general, the benefits of e-prescribing fall into the following categories: patient safety, improved prescribing, efficiency/workflow, and cost savings. Most literature to date has focused on the benefits to prescribers. This review summarizes the existing literature around the impact of e-prescribing on pharmacists and patients. While there are studies supporting many of the proposed benefits to pharmacies, such as increased legibility of prescriptions and improved workflow, there have also been studies that demonstrate unintended challenges brought about by e-prescribing. Likewise, studies examining the patient's experience with e-prescribing make it clear that patients do not always see all of the benefits of e-prescribing, which happen away from their view. There are opportunities for additional research and development of new technologies to improve the e-prescribing experience for both pharmacists and patients.
\end{abstract}

Keywords: e-prescribing, community pharmacy, medication error, workflow

\section{Introduction}

Electronic prescribing (e-prescribing) is defined by the US' Centers for Medicare \& Medicaid Services (CMS) as

[...] the transmission using electronic media, of prescription or prescription-related information between a prescriber, dispenser, pharmacy benefit manager, or health plan, either directly or through an intermediary, including an e-prescribing network. E-prescribing includes, but is not limited to, two-way transmissions between the point of care and the dispenser. ${ }^{1}$

While the technologies used are similar, for this review we will focus on outpatient e-prescribing as opposed to computerized physician order entry, which takes place in a hospital setting. In many cases, e-prescribing software platforms also include point-of-care decision support that alerts prescribers to potential prescription errors at the time of prescribing. E-prescribing is one part of the larger move to increased utilization of health information technologies (HITs). Along with other HITs such as electronic health records (EHRs) and health information exchanges, e-prescribing is seen as a tool for improving patient-centered care.
Correspondence: Donald G Klepser Department of Pharmacy Practice, College of Pharmacy, University of Nebraska Medical Center, 986045 Nebraska Medical Center, Omaha, NE 68198-6045, USA

Tel +l 4025594927

Fax +I 4025595673

Email dklepser@unmc.edu (c) (i) (5) 2016 Lanham et al. This work is published and licensed by Dove Medical Press Limited. The full terms of this license are available at https://www.dovepress.com/terms. BY NG php and incorporate the Creative Commons Attribution - Non Commercial (unported, v3.0) License (http://(creativecommons.org/licenses/lby-nc/3.0/). By accessing the vork. you hereby accept his iemp. Non-commercial wes of the work are permitted without any further permission from Dove Medical Press Limited, provided the work is properly attributed. For permission for commercial use of this work, please see paragraphs 4.2 and 5 of our Terms (https://www.dovepress.com/terms.php) 
In the US and other countries, significant public and private investments have been made to increase installation of these technologies. CMS has developed a series of meaningful use guidelines along with financial incentives and penalties to move utilization toward certain e-prescribing targets (ie, $40 \%$ of all prescriptions were required to be e-prescribed by 2012 in order to avoid a 1\% reduction in Medicare payments). Similar financial incentives to spur adoption have also been seen in other countries, including the UK and the Netherlands. ${ }^{2}$ As a result of these coordinated efforts, adoption of e-prescribing technology has grown rapidly among both prescribers and pharmacies. A July 2014 data brief from the US' Office of the National Coordinator estimated that $70 \%$ of US physicians were e-prescribing through an EHR compared to $7 \%$ in 2008 and $24 \%$ in $2011 .^{3}$ This adoption rate trails the rates seen in some European countries, but still points toward significant growth. By comparison and despite a lack of direct financial incentives, $96 \%$ of community pharmacies in the US were enabled to accept electronic-prescriptions (e-prescriptions) in 2014. ${ }^{3}$ The growth of physicians and pharmacies e-prescribing has corresponded with significant growth of new and renewal prescriptions sent electronically. In 2008 , only $4 \%$ of prescriptions were sent electronically. In $2013,57 \%$ of new and renewal prescriptions were sent electronically. ${ }^{3}$

The potential benefits of e-prescribing are meant to extend to prescribers, payers, pharmacies, and patients. In general, the benefits of e-prescribing fall into the following categories: patient safety, improved prescribing, efficiency/workflow, and cost savings. As with any new technology, a number of potential barriers or challenges to the adoption of e-prescribing were also identified. Those cited most often include the cost of implementing an e-prescribing system, potential e-prescribing system errors, and issues related to privacy and data sharing. ${ }^{4}$ While the benefits and challenges related to e-prescribing may extend to all four stakeholder groups, the majority of research in the ambulatory setting has been on the benefits to and attitudes of prescribers toward e-prescribing. In many ways, this is understandable because prescriber utilization will ultimately drive adoption of e-prescribing technology by pharmacies and patients, which is also why most financial incentives have been aimed at prescriber adoption. Despite this focus, a better understanding of the benefits and challenges to pharmacists and patients, including their perceptions of e-prescribing, is important for the widespread adoption and development of future e-prescribing platforms.
The purpose of this paper is to review and discuss the existing literature on the impact of e-prescribing on pharmacists and patients.

\section{Methods}

For this narrative review, we conducted a literature search in PubMed during the first week of March 2015 using the terms "e-prescribing" and "electronic prescribing" with "pharmacist", "pharmacy", or "patient". We searched for publications between January 2000 and February 2015. We also conducted a Google search using the same terms to identify publications in the lay press. We reviewed all manuscripts to identify those related to the benefits and challenges of e-prescribing from the pharmacist or patient perspective. The proposed benefits and challenges of e-prescribing are given as an outline, and the remainder of the paper describes the evidence supporting or challenging the realization of the proposed benefits of e-prescribing to pharmacists and patients.

\section{Results}

\section{Patient safety/medication errors}

The Institute of Medicine report To Err Is Human: Building a Safer Health System reported that medication errors were estimated to have accounted for approximately 7,000 deaths in 1993 and caused one out of 131 outpatient deaths. ${ }^{5}$ Since the time of that report, a great deal of attention has been paid to medication errors, and efforts have been made to improve patient safety. Not only do medication errors have a serious impact on patient well-being, they may also result in the loss of patient trust, disciplinary action by the medical and pharmacy boards, and even civil actions and criminal charges. ${ }^{6}$ While most medication errors that reach the patient do not cause harm to the patient, ${ }^{7,8}$ any technology or process that reduces errors in the more than 4 billion prescriptions dispensed annually is a clear benefit to the patient, prescriber, and pharmacist.

Research on the impact of e-prescribing on medication errors has typically taken place in hospital settings or looked at specific populations or medications. ${ }^{9}$ There is some evidence to suggest that e-prescribing can reduce medication errors; ${ }^{9-11}$ however, some errors still persist. ${ }^{9,12-17}$ The most obvious benefit of e-prescribing on medication errors involves prescription legibility. To identify the types of prescribing errors in the ambulatory care setting, Abramson et $\mathrm{al}^{10}$ analyzed 9,385 paper prescriptions from 78 providers and found an overall prescribing error rate, excluding illegibility errors, of 36.7 per 100 prescriptions. Illegibility errors were very high, and inappropriate abbreviation and direction errors also occurred frequently. ${ }^{10}$ The study reviewers 
concluded that e-prescribing with clinical decision support could eliminate a vast majority of the errors. ${ }^{10}$ In addition, Kaushal et $\mathrm{al}^{18}$ found a nearly sevenfold decrease in error rates, from 42.5 per 100 prescriptions before adoption of e-prescribing, or baseline, to 6.6 per 100 prescriptions 1 year after adoption.

Research conducted in the community pharmacy setting has focused on errors still found in e-prescriptions and how they can be alleviated. The most common e-prescribing errors observed and reported in literature are wrong quantity, wrong directions, wrong dosage, wrong dosage form, wrong days' supply, wrong drug, and wrong patient. ${ }^{19-21}$ A number of factors may contribute to these errors. Several studies have noted the drop-down menus and pick-lists as an e-prescribing system challenges that may contribute to selection of the wrong information..$^{15,22,23}$ Nanji et al ${ }^{17}$ identified $452(11.7 \%)$ errors contained in 3,850 computer-generated prescriptions reviewed, 163 (35\%) of which were considered potential adverse drug events. The errors were identified by reviewing prescriptions received by outpatient pharmacies. The evaluation did not include errors that originated within the pharmacy or the number of clarifications initiated by pharmacists to address errors that were identified during a pharmacist's review of the prescription. The inclusion of forcing functions to ensure that all required information is present and integration of drug decision-support systems such as maximum dose checkers and dose calculators into prescribing software have been recommended to reduce e-prescribing errors. ${ }^{17}$

Discrepancies have also been described within an electronic prescription (e-prescription). For example, structured fields like dose may not agree with the dose entered into a free-text field. Prescribers may select a dose from a dropdown menu, but then type a different dose in an "Additional Instructions" field. ${ }^{12,24}$

Errors can also occur once the e-prescription is received by the pharmacy. E-prescriptions often require manipulation by pharmacy staff due to system design limitations, such as completing or editing certain fields, thus allowing for other opportunities for transcribing errors. ${ }^{25}$

So while it is anticipated that the net effect of e-prescribing is a reduction in medication errors, there have been a number of studies examining the impact of e-prescribing on pharmacist workflow. Pharmacists serve as the final health care professional in the line of defense between the medication and the patient. One study measuring the intervention of pharmacists on e-prescriptions versus traditional prescriptions found an e-prescribing intervention rate of $11.7 \%$ and a handwritten prescription intervention rate of $15.4 \%$; results were not statistically significant. ${ }^{26}$ Odukoya et $\mathrm{al}^{27}$ studied the processes by which pharmacy personnel recover from e-prescription errors and established that error detection was accomplished through a number of strategies. These strategies included 1) double checking for accuracy by different pharmacy personnel throughout the pharmacy workflow, 2) printing out the hard copy of an e-prescription to allow personnel to more easily recognize errors, and 3) highlighting key information on the printed e-prescription to allow for easy identification of pertinent information. Researchers also identified ways in which pharmacy personnel explain and, finally, solve the error. Participants reported consultation with another pharmacy team member, review of patient's medication history, pharmacist consultation with patient, and use of online drug information as strategies for explaining e-prescribing errors. To solve the errors, respondents reported that contacting the prescriber by telephone was the most frequently used of the strategies. Others strategies reported by respondents included contacting the prescriber by fax or making an educated guess of the prescriber's intent, which respondents stated was particularly common with wrong quantity errors for creams and ointments. ${ }^{27}$

E-prescribing certainly has been shown to reduce some types of medication errors, but it has also, as any new system would, created new types of errors. We were unable to find definitive studies showing the net benefit of e-prescribing on medication errors. As we look forward to results from such definitive studies, it is heartening to know that pharmacists, researchers, and policymakers continue to push for the better e-prescribing platforms that address some of the existing challenges.

\section{Improved prescribing}

Often when health care professionals talk about medication administration they talk about the "five rights" of medication use: the right patient, the right drug, the right time, the right dose, and the right route. ${ }^{28}$ All five are important to safe medication practices and reducing errors, but getting all five pieces correct, particularly the right drug and dose, for each patient involves access to information about that patient at the time of prescribing and dispensing. Moreover, the "best" prescription for each patient may also be dependent on nonclinical factors such as cost and access. Understanding the individual circumstances of each patient may improve overall prescribing, and e-prescribing systems may play an important role in improving prescribing and reducing time spent by pharmacists and physicians addressing issues on the back end. 
With innovations in e-prescribing, physicians have access to patient medication histories, clinical decision-support systems, insurance plan formularies, and electronic prior authorizations, which have the potential to help improve prescribing and avoid errors in prescribing. Some e-prescribing systems provide full access to the patient medication history to the prescriber at the point of prescribing. Physicians have suggested that having a medication list that is typically more comprehensive than paper charts is one value of e-prescriptions. ${ }^{29}$ Some e-prescribing systems even allow for a real-time data stream of the patient fill history so that providers can assess for medication adherence. ${ }^{30} \mathrm{Clinical}$ decision support checks for drug-drug interactions, drug-allergy interactions, and drug-disease interactions and integrates drug costs and dosing recommendations. ${ }^{4}$ Alert fatigue can develop as a result of alert overload. Studies have shown that providers often perceive the alerts as irrelevant, and therefore providers frequently override alerts. ${ }^{31-36}$

E-prescribing systems also allow providers to access which medications are covered on the plans' formularies at the point of prescribing. ${ }^{30}$ This system function has the potential to generate significant cost savings for patients and the health care system. In 2008, Fischer et al ${ }^{37}$ found that e-prescribing with formulary decision support led to a $3.3 \%$ increase in tier 1 prescribing and a corresponding decrease in tiers 2 and 3 prescribing. The study also estimated that e-prescribing at this rate could generate savings of $\$ 845,000$ per 100,000 patients. ${ }^{37}$ One study found that most patients who had received an e-prescription were at least sometimes worried about costs of drugs, but only about half of the respondents' doctors discussed costs of drugs with the patients. ${ }^{30} \mathrm{~A}$ more recent study found that $14.3 \%$ of patients using e-prescriptions discussed cost with their doctor while no patients using paper prescriptions did. ${ }^{38}$ This research suggests that providers should have drug cost discussions with patients with all the information available at the time of prescribing. One limitation to this is the fact that e-prescribing systems do not have "real cost" data of medications, ${ }^{30}$ which is imperative for patients in the Medicare Part D "doughnut hole" or with no insurance coverage and limited financial resources.

Tremendous progress has also been made toward electronic prior authorizations. A prior authorization is an approval from a health plan that might be required before a prescription can be covered by the plan. ${ }^{39}$ Before electronic prior authorizations, the process was a huge hurdle for all parties involved, patients, pharmacies, and providers. Electronic prior authorization is accomplished through computer-to-computer information transmission between the pharmacy and the prescriber. This is a great improvement over the paper process, which involves numerous phone calls and faxes, and can take several days. Electronic prior authorization streamlines the process for the pharmacies and providers, getting the medication to the patient quickly and efficiently. ${ }^{40}$ In 2010, the Drug Enforcement Agency (DEA) issued guidelines for e-prescribing for controlled substances (78 FR 18364). The potential benefits of e-prescribing of controlled substances include reduction of the prescription fraud typically associated with paper prescriptions and medication reconciliation at the point of prescribing to reduce order duplication. ${ }^{41}$

Overall, the potential improvements to prescribing related to e-prescribing will be largely dependent on the uptake of the many system functions of the e-prescribing systems, namely patient medication histories, access to insurance plan formularies, and electronic prior authorization. Research suggests that patients perceive an improvement in care. In a recent study of older adults, Schleiden et $\mathrm{a}^{38}$ found that $64.8 \%$ of patients who received e-prescriptions believed that e-prescribing had improved the care they received from their doctor or nurse at least a little, while $63.6 \%$ of patients believed that e-prescribing improved the care from their pharmacist at least a little.

One promise of e-prescribing was to increase information sharing between health care providers. The results of one pilot study suggest that adding a patient diagnosis to an e-prescription significantly lowers pharmacist intervention rates and can reduce uncertainty and confusion for the pharmacist, ${ }^{42}$ but diagnosis is not consistently included in e-prescriptions.

Through improved access to patient specific information at the time of prescribing and dispensing, e-prescribing is likely to improve prescribing. The current challenge to realizing those benefits is ensuring systems have the capability to utilize the information in an efficient manner, and that health care providers use the information when it is available.

\section{Primary medication nonadherence}

In the US, it is estimated that medication nonadherence could result in $\$ 290$ billion per year in avoidable medical spending. ${ }^{43}$ Prior to recent advances in e-prescribing, much of the medication adherence research focused on secondary medication nonadherence, which describes adherence once a prescription has been filled and refilled. ${ }^{44,45}$ It was difficult to track the fill of initial prescriptions, which were almost 
always handwritten and could be lost, misplaced, forgotten, or ignored. Because the pharmacist was not even aware of the prescription, and the physician likely assumed that the prescription was filled, there was little that could be done to determine whether or not patients were filling prescriptions for needed medications.

E-prescribing creates the ability to track primary medication nonadherence $(\mathrm{PMN})$ rates $^{46}$ and creates opportunities for pharmacists to intervene. ${ }^{47}$ Primary medication adherence is adherence to the first fill of a prescribed medication. ${ }^{48,49}$ Recent research has shown that as many as $24 \%$ of e-prescriptions for new medications are prescribed and not filled. ${ }^{45}$ To facilitate the measurement of PMN, the Pharmacy Quality Alliance developed and endorsed an initial PMN quality measure designed for community pharmacies..$^{50}$ The benefits of improved PMN extend to all stakeholders, including the pharmacy, which sees an increase in revenue from the number of prescriptions filled, and the patient, whose use of effective treatments is likely to improve clinical outcomes and downstream expenses.

To measure the impact of e-prescribing on PMN, one study analyzed over 40 million prescription records and found a consistent $10 \%$ increase in patient first-fill medication adherence among physicians who used e-prescribing compared to physicians who did not use e-prescribing. ${ }^{51}$ Another study established that by adding live intervention by a pharmacist or pharmacy technician, new prescription abandonment was reduced by almost $5 \%{ }^{47}$

Research has been conducted to gather the perceptions of patients on medication adherence with e-prescribing. Lapane et $\mathrm{al}^{30}$ were the first to study patient perceptions in geriatric patients. Researchers found that patients felt e-prescribing had somewhat increased discussions about adherence with their provider compared to patients who did not receive e-prescriptions. ${ }^{30}$ The study concluded that regardless of whether the patients received an e-prescription, $75 \%$ of geriatric patients reported that they did not tell their physician if they did not want a prescription, and $85 \%$ reported that they never tell their provider if they do not intend to purchase a prescription. ${ }^{30} \mathrm{~A}$ more recent study concluded that most patients receiving an e-prescription did not believe their adherence had improved. ${ }^{38}$

The costs incurred by the pharmacy and payer to fill a prescription that a patient never picks up is referred to by the industry as "leakage". It is hypothesized that it will increase with e-prescriptions. ${ }^{30}$ A recent study by Shrank et $\mathrm{al}^{52} \mathrm{did}$ estimate that prescriptions delivered electronically were 1.64 times more likely to be abandoned than those that were not electronic. ${ }^{52}$ While an "abandoned" prescription can generally be returned to stock and resold, the cost of dispensing or processing the initial prescription is not recouped. In a national cost of dispensing study released in 2007, the average overall cost of dispensing per prescription was $\$ 10.50 .^{53}$ Future research should further seek to quantify "leakage" as well as if or how e-prescribing contributes to it.

\section{Efficiency/workflow}

To understand how an e-prescribing system could improve a pharmacy's workflow, it is important to understand existing models of how a prescription is filled at the pharmacy and where the e-prescribing could make an impact. In addition to e-prescribing, a prescription can arrive at the pharmacy either as a handwritten, hard copy brought to the pharmacy by the patient, via fax from the physician's office, or by phone call from physician's office. In all cases, the prescription information received at the pharmacy must be transcribed or input into the pharmacy's computer system. If the pharmacist is unable to read the physician's handwriting, he/she must contact the physician for clarification. Once entered into the system, the pharmacist or pharmacy technician is alerted to potential safety (eg, drug-drug interaction, allergies, etc) or formulary issues. If there are issues with the prescription, the pharmacist must contact the prescriber for resolution. Once the prescription information is entered into the pharmacy's system, the remaining steps in dispensing the prescription (ie, counting the tablets, counseling the patient, etc) are the same regardless of how the prescription arrives at the pharmacy.

E-prescribing has the potential to improve the pharmacy workflow by addressing issues related to transcription, calls to the physician, and patients queuing up for their prescriptions. A sample pharmacy workflow for an e-prescription is represented in Figure 1.

If the physician's e-prescribing software is compatible with the pharmacy's system, it would eliminate the need for pharmacists to transcribe the prescription into their software. Similarly, e-prescriptions, even if they did need to be transcribed, are typed, which should eliminate calls needed for illegible handwriting. In addition, providing the physician with safety and formulary information at the time of prescribing should eliminate calls from the pharmacy seeking to clarify issues. Finally, e-prescriptions sent from the physician's office at the time of the patient's visit should allow the pharmacist an opportunity to better manage which prescriptions get filled first, as the patient is no longer bringing the prescription into the pharmacy and waiting for it to be filled. This also represents the biggest potential time savings to the patient. 

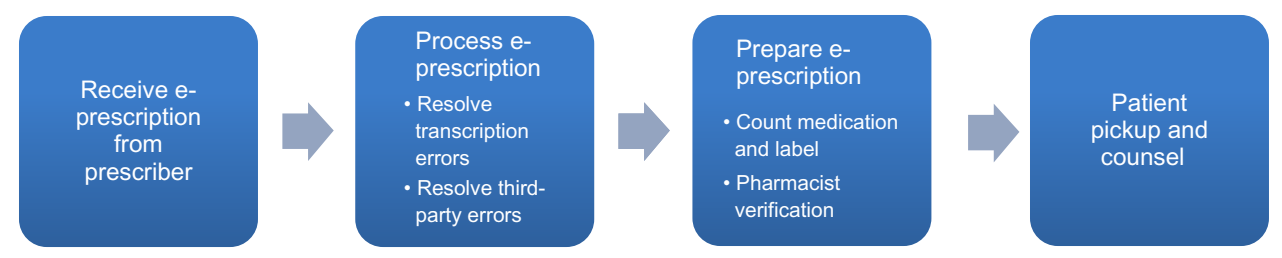

Figure I Sample pharmacy workflow for an e-prescription.

Abbreviation: e-prescription, electronic prescription.

E-prescriptions have been shown to improve staff productivity when compared to traditional forms of prescription. ${ }^{54}$ A 2004 study found that new e-prescriptions required on average $26.2 \%$ less staff time when compared to other new prescriptions. ${ }^{54}$ The value of e-prescribing to the pharmacy workflow comes from the ability to cut out most of the prescription drop-off and transcription process. Rupp and Warholak ${ }^{20}$ measured the attitudes and beliefs of communitybased pharmacy professionals toward e-prescribing. The top positive features of e-prescribing included improved legibility/clarity, improved speed/efficiency, and reduced interruptions. ${ }^{20}$ Respondents also noted potential concerns, with prescribing errors, delays in receiving the e-prescription, and technical problems, being in the top three. ${ }^{20}$ Table 1 describes the strengths and potential challenges of the design of e-prescriptions reported by retail pharmacy staff..$^{55}$

In England, Harvey et $a^{156}$ interviewed pharmacy professionals who were early adopters of the Electronic Prescription Service, which allows prescriptions to be downloaded from the Spine, the national central database. Respondents noted that the electronic system allowed them to smooth workflow, organize dispensing activities, and improve ordering of drugs. ${ }^{56}$ Respondents did experience some glitches, with missing prescriptions and download problems being the most notable. ${ }^{56}$ Lost prescriptions became a point of contention between the pharmacy and the general practice (GP) prescribers as well as the pharmacy and the patient. ${ }^{56}$ Other reported issues with the system included GP prescribers forgetting to sign the prescriptions electronically, the system automatically generating expiration dates, and slow process times of the Spine. Overall, the pharmacy professionals that were interviewed reported that the Electronic Prescription Service had made their lives easier. ${ }^{56}$

While the literature certainly supports the potential for e-prescribing to improve workflow, a study by Boals et al ${ }^{57}$ highlights two issues related to any efficiency gains a pharmacy may see from e-prescribing. In this time and motion study of four rural pharmacies, e-prescribing did reduce transcription time and the time needed to fill a prescription. However, because the pharmacies all continued

Table I Strengths and challenges in the design of e-prescriptions

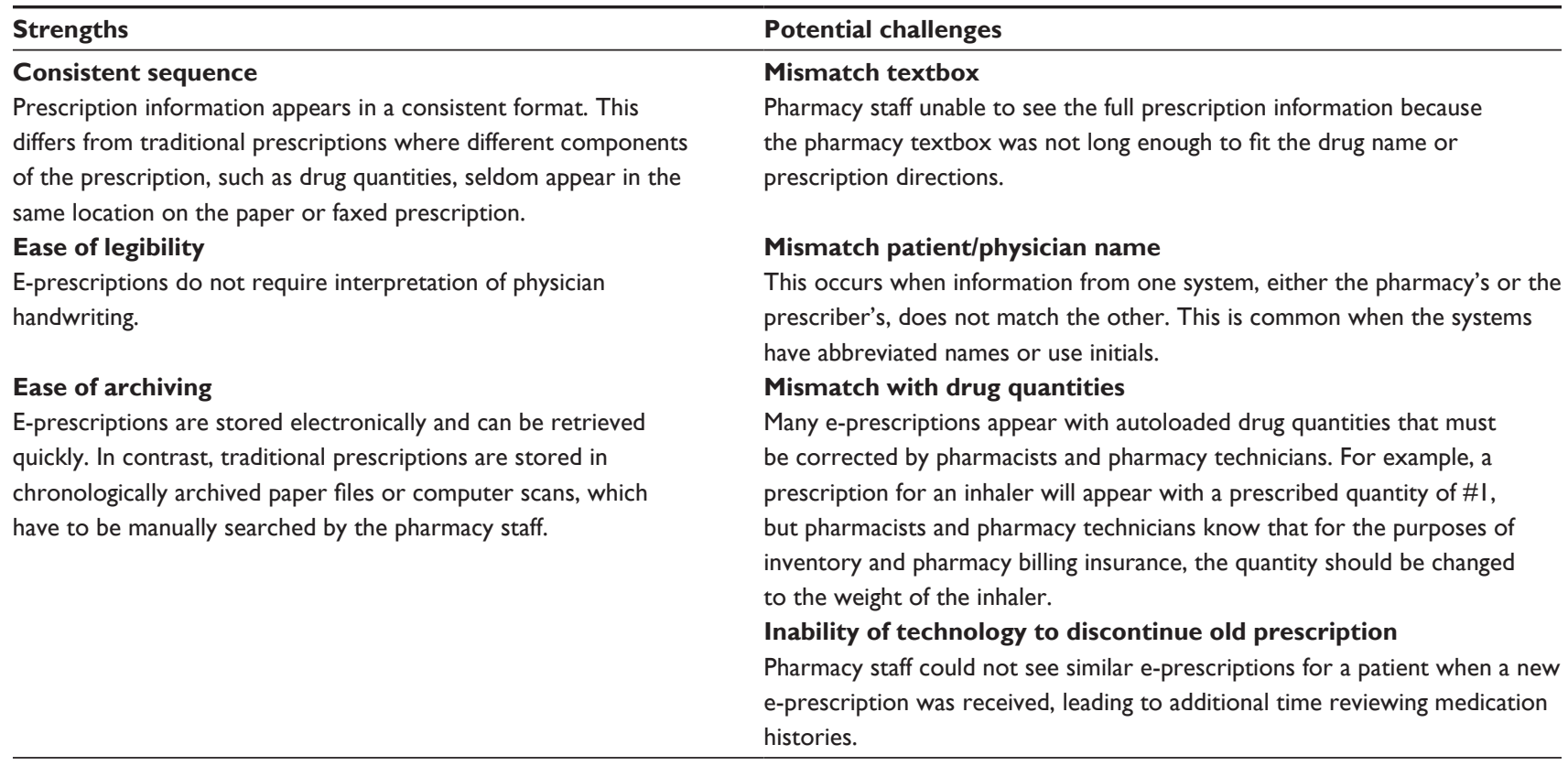

Note: According to data from Odukoya and Chui. ${ }^{55}$

Abbreviation: e-prescription, electronic prescription. 
to receive prescriptions via hard copy, fax, and phone, they could not focus their staffing and workflow to the potential savings realized through e-prescribing. In other words, though an e-prescription may have taken 60-90 seconds less to fill, those savings were not consistent enough to justify lower staffing levels. In addition, these rural pharmacies all had excess capacity and limited opportunities to grow prescription volume, so the productivity gains did not lead to additional revenue for the pharmacy. Thus, while e-prescribing may have increased efficiency for the pharmacies, those gains did not translate directly to increased profitability.

In addition to challenges in capturing the value of workflow gains, e-prescribing has created some new workflow challenges. Delays can occur on the prescriber and pharmacy side. For example, prescribers might not submit the e-prescription right after a patient visit, therefore leading to delays at the pharmacy, and often resulting in a phone call from the pharmacy to the prescriber's office after a patient waits for an extended period of time..$^{58}$ One study found that elderly population patients receiving e-prescriptions had higher expectations of pharmacies related to readiness of the medication; most of the patients expected their e-prescription to be ready within a few hours or immediately. ${ }^{30}$ In the same study, patients receiving e-prescriptions reported greater satisfaction with pharmacies when compared to patients who did not. ${ }^{30}$

In an era of drive-thru windows and health care automation, e-prescribing provides another point of convenience for patients. Now, instead of patients dropping off their prescriptions and returning later to pick them up, patients can visit the pharmacy once for medication pickup. Recent data suggest that patients now prefer e-prescriptions over paper prescriptions. ${ }^{38} \mathrm{~A}$ recent study by Schleiden et $\mathrm{al}^{38}$ involving patients over 50 years old found that approximately $80 \%$ of the patients preferred e-prescriptions to paper prescriptions. Patients' preference for e-prescriptions was typically related to convenience. In the same study, a vast majority of the patients who received e-prescriptions reported being very satisfied with their doctor (92.9\%) sending it and their pharmacy $(84.2 \%)$ receiving it. ${ }^{38}$

\section{Costs and incentives}

Having the installed infrastructure to support e-prescribing, especially with the kind of clinical support needed to improve prescribing, requires a financial commitment on the part of both prescribers and pharmacies. Since most pharmacies in the US and other developed countries already had computer systems in place to process prescription transactions, the infrastructure costs to pharmacies were generally lower. As recently as 2010, only a relatively small percentage of prescribers had access to a system capable of e-prescribing. ${ }^{3}$ Moreover, the financial investment needed on the prescriber side is generally much larger as it includes movement from paper-based to electronic medical records. As a result, and because it is often and rightly assumed that physician adoption of e-prescribing drives pharmacy adoption, the financial costs and incentives of e-prescribing have been very different for physicians and pharmacies.

E-prescribing rates began to increase with the passing of the Medicare Prescription Drug, Improvement, and Modernization Act (MMA) of 2003, which in 2006 established Medicare Part D, the prescription drug coverage under Medicare. Although MMA did not require e-prescribing, it did set standards by which e-prescriptions should be sent. In addition, as a part the Health Information Technology for Economic and Clinical Health (HITECH) Act, meaningful use standards set by CMS arranged incentives for physicians to use e-prescribing, thus increasing the use of the e-prescribing. ${ }^{4}$ Meaningful use is using technology to improve quality, safety, efficiency, and reduce health disparities. ${ }^{59}$

Physicians are eligible to receive payment incentives for participating in meaningful use. On the other hand, pharmacies pay transaction fees associated with processing e-prescriptions. These transaction fees have been reported to between $\$ 0.20$ and $\$ 0.30$ for each new prescription. ${ }^{60}$ E-prescribing has been shown to create efficiencies that lead to cost savings. One study found that new e-prescriptions required $26.6 \%$ less staff time to process compared to other new prescriptions, leading to an estimated costs saving of $\$ 0.97$ per prescription. The same study found refill e-prescriptions to require $10.2 \%$ less staff time and $\$ 0.37$ in estimated savings per prescription. ${ }^{54}$

No rigorous studies have been conducted to demonstrate whether e-prescribing has had a positive or negative impact on pharmacy margins, in part because there are always other factors at play that impact those margins. What is known is that many pharmacists and pharmacy owners perceive the costs associated with e-prescribing to be a barrier to implementation. ${ }^{60}$ Anecdotal evidence and responses have even suggested that some pharmacies have asked physicians to "e-prescribe to fax" as a way of avoiding the transaction fees associated with receiving e-prescriptions. ${ }^{60}$ In the end, any additional costs of e-prescribing will be passed along to patients and their payers, although there is no literature exploring that impact. 


\section{Perceptions/privacy}

While increased costs would certainly be a major concern for patients, their perceptions of e-prescribing tend to be driven by personal experiences and concerns about privacy. The studies on e-prescribing tend to confirm that thinking.

Much can be learned from the patient perception data related to e-prescribing to date..$^{30,38,61}$ Table 2 summarizes the findings of these studies.

Patients report positive perceptions centered on convenience, quality, and costs; the negative perceptions were connected to communication, control of prescriptions, and prescription misdirection. ${ }^{38,61}$

E-prescribing creates some communication opportunities and challenges for patients, providers, and pharmacies. E-prescribing creates a clear channel of communication between prescribers and pharmacies, avoiding illegible handwritten paper prescriptions. From the patient perception, e-prescribing causes some communication barriers. ${ }^{61}$ Frail et $\mathrm{a}^{61}$ found that patients felt that providers were directing their attention to the computer rather than the patient. This patient experience was likely due to the overall adoption of EHRs, and not just e-prescribing alone. Another communication barrier is the inability of the patients to access the drug name they are prescribed prior to arriving in the pharmacy. ${ }^{61}$ A possible solution to this barrier would be for prescribers to give patients a printout of the medications being e-prescribed or medication information related to the drugs being e-prescribed..$^{30}$ The name of the pharmacy to which the e-prescription was sent would also be helpful information, especially for elderly patients and patients who use multiple pharmacies.

E-prescribing, like other forms of EHRs, stores and transfers personal health information, thus raising concerns about privacy of patient information. ${ }^{62}$ The Health Insurance Portability and Accountability Act of 1996 (HIPAA) allowed federal regulation to safeguard patient health information, which includes e-prescription information (42 CFR $\S 164.501)$. To our surprise, patient privacy was not reported as a concern or negative perception of e-prescribing in any of the studies with objectives to describe the perceptions of patients on e-prescribing. ${ }^{30,38,61}$

\section{Security concerns}

While HIPAA provides guidance and requirements for protecting patient information, we know that electronically transmitted and stored data are susceptible to a host of security issues such as hacking and virus attacks. Such security issues may lead to breaches of patient privacy, but they may also be used for other criminal purposes such as inappropriate prescribing of controlled substances or highcost medications. While most e-prescribing systems do have safeguards in place to protect access, they are susceptible to attack. There has been a report from Turkey of e-prescription system being hacked and passwords used to obtain medicine illegally. ${ }^{63} \mathrm{~A}$ single review has looked at the point of security risks, but little research has been done in the area to identify the impact of these issues on pharmacists or patients. ${ }^{64}$

\section{Conclusion}

E-prescribing has grown dramatically in the community setting over the past 5 years, and there is no indication that the growth is stalling or that the system will ever revert to paper-based prescribing. In fact, recent regulatory changes in the US allowing e-prescribing of controlled substances makes it possible to move all prescribing to e-prescribing. And while it is unlikely that all prescriptions will be e-prescribed in the near future, as it becomes the dominant method, the impact on pharmacists and patients is likely to evolve as benefits are more fully realized and current challenges are addressed. The push toward implementation of e-prescribing was made

Table 2 Patient perceptions of e-prescribing

\begin{tabular}{ll}
\hline Positive perceptions & Negative perceptions \\
\hline - Reduced overall cost to the health care system and personal medication & - Communication challenges with pharmacists and prescribers \\
expenditure through formulary function & \\
- Reduction in medication errors & - Prescriptions being sent to the wrong pharmacy \\
- Increased access to information for prescribers ${ }^{\mathrm{a}}$ & - Feeling of less control over their prescriptions ${ }^{\mathrm{a}, \mathrm{b}}$ \\
- Availability of after-visit summary & - No access to drug name prescribed until reaching the pharmacy \\
- Convenience through time savings & - Not able to delay prescription fill to later date \\
- Reduced number of visits the to the doctor and pharmacy & \\
- Prevention of lost or destroyed prescriptions & \\
- Avoids illegible prescriptions &
\end{tabular}

Notes: according to data from Frail et al. ${ }^{61}$ beccording to data from Schleiden et al. ${ }^{38}$ Abbreviation: e-prescribing, electronic prescribing. 
based on the potential benefits to the various stakeholders, including pharmacists and patients. As is the case with any process change or technology advance, the implementation of e-prescribing has had unintended consequences, both positive and negative.

Going forward, there are opportunities for researchers, policy makers, and technology vendors to work with all stakeholders to improve the system. Researchers should now be looking at how e-prescribing systems are being used and how they could be better used to improve outcomes. Likewise, policymakers should be considering their role after widespread implementation is achieved. In particular, they should be considering policies that move toward better prescribing and not just e-prescribing. Finally, technology vendors should be considering how to make the next-generation platforms more user-friendly and integrated into other systems so that the full advantage of e-prescribing can be realized.

\section{Acknowledgment}

Dr Lanham has had a change in employment and would like to acknowledge that at time of writing this paper, her affiliation was with the National Association of Chain Drug Stores (NACDS) Foundation, Arlington, VA, USA, which is where the authorship occurred.

\section{Disclosure}

The authors report no conflicts of interest in this work.

\section{References}

1. Electronic prescription drug program [42 CFR §423.159]. In: Code of Federal Regulations (annual edition). Centers for Medicare \& Medicaid Services, Department of Health and Human Services, US Government Publishing Office; 2012. Available from: https://www.gpo.gov/fdsys/ pkg/CFR-2012-title42-vol3/pdf/CFR-2012-title42-vol3-sec423-159.pdf. Accessed February 16, 2015.

2. Villalba Van Dijk L, De Vries H, Bell DS. Electronic Prescribing in the United Kingdom and in the Netherlands. AHRQ publication no 11-0044EF. Rockville, MD: Agency for Healthcare Research and Quality; 2011. Available from: http:/healthit.ahrq.gov/sites/default/files/docs/citation/ europe-e-prescribing-report.pdf. Accessed February 16, 2015.

3. Gabriel MH, Swain M. E-prescribing trends in the United States. ONC data brief, no 18. Washington, DC: Office of the National Coordinator for Health Information Technology; 2014. Available from: http://healthit.gov/ sites/default/files/oncdatabriefe-prescribingincreases2014.pdf. Accessed February 16, 2015.

4. Porterfield A, Engelbert K, Coustasse A. Electronic prescribing: improving the efficiency and accuracy of prescribing in the ambulatory care setting. Perspect Health Inf Manag. 2014;11:1g.

5. Kohn LT, Corrigan J, Donaldson MS. Institute of Medicine. To Err is Human: Building a Safer Health System. Washington, DC: National Academy Press; 1999.

6. Wittich CM, Burkle, CM, Lanier LL. Medication errors: an overview for clinicians. Mayo Clin Proc. 2014;89(8):1116-1125.

7. Barker KN, Flynn EA, Pepper GA, Bates DW, Mikeal RL. Medication errors observed in 36 health care facilities. Arch Intern Med. 2002;162(16):1897-1903.
8. Bates DW, Boyle DL, Vander Vliet MB, Schneider J, Leape L. Relationship between medication errors and adverse drug events. J Gen Intern Med. 1995;10(4):199-205.

9. Ammenwerth E, Schnell-Inderst P, Machan C, Siebert U. The effect of electronic prescribing on medication errors and adverse drug events: a systematic review. J Am Med Inform Assoc. 2008;15(5):585-600.

10. Abramson EL, Bates DW, Jenter C, et al. Ambulatory prescribing errors among community-based providers in two states. $J$ Am Med Inform Assoc. 2012;19:644-648.

11. McKibbon KA, Lokker C, Handler SM, et al. Enabling Medication Management Through Health Information Technology. Evidence Report/ Technology Assessment no 201 (Prepared by the McMaster University Evidence-based Practice Center under Contract HHSA 290-200710060-I). AHRQ publication no 11-E008-EF. Rockville, MD: Agency for Healthcare Research and Quality; 2011.

12. Palchuk MB, Fang EA, Cygielnik JM, et al. An unintended consequence of electronic prescriptions: prevalence and impact of internal discrepancies. J Am Med Inform Assoc. 2010;17:472-476.

13. Koppel R, Metlay JP, Cohen A, et al. Role of computerized physician order entry systems in facilitating medication errors. JAMA. 2005;293:1197-1203.

14. Berger RG, Kichak JP. Computerized physician order entry: helpful or harmful? J Am Med Inform Assoc. 2004;11:100-103.

15. Horsky J, Kuperman GJ, Patel VL. Comprehensive analysis of a medication dosing error related to CPOE. J Am Med Inform Assoc. 2005; 12:377-382.

16. Campbell EM, Sittig DF, Ash JS, et al. Types of unintended consequences related to computerized provider order entry. JAm Med Inform Assoc. 2006;13:547-556.

17. Nanji KC, Rothschild JM, Salzberg C, et al. Errors associated with outpatient computerized prescribing systems. J Am Med Inform Assoc. 2011;18:767-773.

18. Kaushal R, Kern LM, Barrón Y, Quaresimo J, Abramson EL. Electronic prescribing improves medication safety in community-based office practices. J Gen Intern Med. 2010;25(6):530-536.

19. Odukoya OK, Stone JA, Chui MA. E-prescribing errors in community pharmacies: exploring consequences and contributing factors. Int $J$ Med Inform. 2014;83(6):427-437.

20. Rupp MT, Warholak TL. Evaluation of e-prescribing in chain community pharmacy: best-practice recommendations. JAm Pharm Assoc. 2008;48:364-370.

21. Warholak TL, Rupp MT. Analysis of community chain pharmacists' interventions on electronic prescriptions. J Am Pharm Assoc. 2009;49:59-64.

22. Smith M, Dang D, Lee J. E-prescribing: clinical implications for patients with diabetes. J Diabetes Sci Technol. 2009;3(5): $1215-1218$.

23. Lapane KL, Waring ME, Dubé C, Schneider KL. E-prescribing and patient safety: results from a mixed method study. Am JPharm Benefits. 2011;3(2):e24-e34.

24. Cochran GL, Klepser DG, Morien M, Lomelin D, Schainost R, Lander L. From physician intent to the pharmacy label: prevalence and description of discrepancies from a cross-sectional evaluation of electronic prescriptions. BMJ Qual Saf. 2014;23:223-230.

25. Grossman JM, Cross DA, Boukus ER, Cohen GR. Transmitting and processing electronic prescriptions: experiences of physician practices and pharmacies. J Am Med Inform Assoc. 2012;19(3): 353-359.

26. Gilligan AM, Miller K, Mohney A, Montenegro C, Schwarz J, Warholak TL. Analysis of pharmacists' interventions on electronic versus traditional prescriptions in 2 community pharmacies. Res Social Adm Pharm. 2012;8(6):523-532.

27. Odukoya OK, Stone JA, Chui MA. How do community pharmacies recover from e-prescription errors? Res Social Adm Pharm. 2014;10(6):837-852.

28. Grissinger M. The five rights: a destination without a map. Pharm Ther. 2010;35(10):542. 
29. Grossman JM, Gerland A, Reed MC, Fahlman C. Physicians' experiences using commercial e-prescribing systems. Health Aff (Millwood). 2007;26(3):393404.

30. Lapane KL, Dubé C, Schneider KL, Quilliam BJ. Patient perceptions regarding electronic prescriptions: is the geriatric patient ready? $\mathrm{J} \mathrm{Am}$ Geriatr Soc. 2007;55(8):1254-1259.

31. Abramson EL, Malhotra S, Fischer K, et al. Transitioning between electronic health records: effects on ambulatory prescribing safety. J Gen Intern Med. 2011;26(8):868-874.

32. Weingart SN, Massagli M, Cyrulik A, et al. Assessing the value of electronic prescribing in ambulatory care: a focus group study. Int J Med Inform. 2009;78(9):571-578.

33. Shah NR, Seger AC, Seger DL, et al. Improving acceptance of computerized prescribing alerts in ambulatory care. $\mathrm{J}$ Am Med Inform Assoc. 2006;13(1):5-11.

34. van der Sijs H, Aarts J, Vulto A, Berg M. Overriding of drug safety alerts in computerized physician order entry. J Am Med Inform Assoc. 2006;13(2):138-147.

35. Taylor LK, Kawasumi Y, Bartlett G, Tamblyn R. Inappropriate prescribing practices: the challenge and opportunity for patient. Healthc $Q$. 2005;8:81-85.

36. Schedlbauer A, Prasad V, Mulvaney C, et al. What evidence supports the use of computerized alerts and prompts to improve clinicians' prescribing behavior? J Am Med Inform Assoc. 2009;16(4):531-538.

37. Fischer MA, Vogeli C, Stedman M, Ferris T, Brookhart M, Weissman JS. Effect of electronic prescribing with formulary decision support on medication use and cost. Arch Intern Med. 2008;168(22):2433-2439.

38. Schleiden LJ, Odukoya OK, Chui MA. Older adults' perceptions of e-prescribing: impact on patient care. Perspect Health Inf Manage. Winter 2015:1-15. Available from: http://perspectives.ahima.org/olderadults-perceptions-of-e-prescribing-impact-on-patient-care/. Accessed February 20, 2015.

39. healthcare.gov. Prior authorization [definition]. Baltimore, MD: U.S. Centers for Medicare and Medicaid Services. Available from: https:// www.healthcare.gov/glossary/prior-authorization/. Accessed February 20, 2015.

40. Bresnick J. Can EHR-based prior authorization improve medication adherence? HealthIT Analytics. December 2014. Available from: http:// healthitanalytics.com/2014/12/02/can-ehr-based-prior-authorizationimprove-medication-adherence/. Accessed February 20, 2015.

41. Perrone J, Nelson LS. Medication reconciliation for controlled substances - an "ideal" prescription-drug monitoring program. $N$ Engl J Med. 2012;366:2341-2343.

42. Warholak TL, Rupp MT, Leal S, Kurniawan G, Patel N. Assessing the effect of providing a pharmacist with patient diagnosis on electronic prescription orders: a pilot study. Res Social Adm Pharm. 2014;10(1):246-251.

43. New England Healthcare Institute. Thinking outside the pillbox: a system-wide approach to improving patient medication adherence for chronic disease. A NEHI Research Brief. August 2009. Available from: http://www.nehi.net/publications/17-thinking-outside-the-pillbox-asystem-wide-approach-to-improving-patient-medication-adherencefor-chronic-disease/view. Accessed February 20, 2015.

44. Shin J, McCombs JS, Sanchez RJ, Udall M, Deminski MC, Cheetham TC. Primary nonadherence to medications in an integrated healthcare setting. Am J Manag Care. 2012;18(8):426-434.

45. Fischer MA, Choudhry NK, Brill G, et al. Trouble getting started: predictors of primary medication nonadherence. Am J Med. 2011;124(11):1081.e9-e22.

46. Fischer MA, Stedman M, Lii J, et al. Primary medication non-adherence: analysis of 195,930 electronic prescriptions. J Gen Intern Med. 2010;25:284-290.
47. Fischer MA, Choudhry NK, Bykov K, et al. Pharmacy-based interventions to reduce primary medication nonadherence to cardiovascular medications. Med Care. 2014;52(12):1050-1054.

48. Andrade SE, Kahler KH, Frech F, Chan KA. Methods for evaluation of medication adherence and persistence using automated databases. Pharmacoepidemiol Drug Saf. 2006;15(8):565-574.

49. Beardon PH, McGilchrist MM, McKendrick AD, McDevitt DG, MacDonald TM. Primary non-compliance with prescribed medication in primary care. $B M J .1993 ; 307(6908): 846-848$.

50. Hubbard TE. Ready for pick-up: reducing primary medication nonadherence. Kennedy A, Bernard L, edtiors. A NEHI Issue Brief. 2014. Available from: http://www.nehi.net/publications/60-ready-for-pick-upreducing-primary-medication-non-adherence/view. Accessed February 20, 2015.

51. Surescripts. Study: e-prescribing shown to improve outcomes and save healthcare system billions of dollars [press release]. Arlington, VA: Surescripts; 2012 [February 1]. Available from: http://surescripts. com/news-center/press-releases/!content/212_eprescribing. Accessed January $12,2016$.

52. Shrank WH, Choudhry NK, Fischer MA, et al. The epidemiology of prescriptions abandoned at the pharmacy. Ann Intern Med. 2010;153:633-640.

53. Grant Thornton LLP. Cost of Dispensing Study: An Independent Comparative Analysis of US Prescription Dispensing Costs. Chicago, IL: Grant Thornton LLP; 2007.

54. Rupp MT. The impact of e-prescribing on staff productivity in community pharmacy: part 1. Computer Talk. 2005;25(3):15-22.

55. Odukoya OK, Chui MA. Retail pharmacy staff perceptions of design strengths and weaknesses of electronic prescribing. J Am Med Inform Assoc. 2012;19:1059-1065.

56. Harvey J, Avery AJ, Barber N. A qualitative study of community pharmacy perceptions of the electronic prescriptions service in England. Int $J$ Pharm Pract. 2014;22(6):440-444.

57. Boals E, Cochran GL, Klepser DE. Electronic prescribing and its impact on rural community pharmacists. Poster Presented Medication Use in Rural America Conference, September 9-11, 2009. Kansas City, MO.

58. Odukoya OK, Chui MA. Relationship between e-prescriptions and community pharmacy workflow. J Am Pharm Assoc. 2012;52(6): e168-e174.

59. HealthIT. Meaningful use definition and objectives. Available from: http://www.healthit.gov/providers-professionals/meaningful-usedefinition-objectives. Accessed February 20, 2015.

60. Lander L, Klepser DG, Cochran GL, Lomelin DE, Morien M. Barrier to electronic prescribing: Nebraska pharmacists' perspective. J Rural Health. 2012:00:1-6.

61. Frail CK, Kline M, Snyder ME. Patient perceptions of e-prescribing and its impact on their relationships with providers: a qualitative analysis. J Am Pharm Assoc. 2014;54:630-633.

62. Greenberg MD, Ridgley MS, Bell DS. Electronic prescribing and HIPAA privacy regulation. Inquiry. 41:461-468.

63. Bozkurt H. Fraud hacks e-prescription system to obtain expensive medications. BGNNews. December 3, 2014. Available from: http:// national.bgnnews.com/fraud-hacks-e-prescription-system-to-obtainexpensive-medications-haberi/1949. Accessed October 13, 2015.

64. Nataraj S. Security concerns in e-prescribing. Rev Bus Inf Syst. Available from: http://cluteinstitute.com/ojs/index.php/RBIS/article/view/3994. Accessed October 13, 2015. 
Advanced Health Care Technologies

Dovepress

\section{Publish your work in this journal}

Advanced Health Care Technologies is an international, peer reviewed, open access journal that provides a unique forum for articles on: point-of-care, health care diagnostics and treatment, bioengineering, biotechnology, biosensing, electronics, clinical/medical science, chemical engineering, materials science, regenerative medicine, micro-/ nano-technologies, and methods and applications for nanoscience and nanotechnology. The manuscript management system is completely online and includes a very quick and fair peer review system, which is all easy to use. Visit http://www.dovepress.com/testimonials.php to read real quotes from published authors.

Submit your manuscript here: http://www.dovepress.com/advanced-health-care-technologies-journal 